\title{
DA RAZÃO INSTITUCIONAL AO VOTO: APLICAÇÃO DA TEORIA DE ALEXY NO RE 845.779
}

FROM THE INSTITUTIONALIZED REASON TO THE DELIBERATION: APPLICATION OF ALEXY'S THEORY IN RE 845.779

DE LA RAZÓN INSTITUCIONAL AL VOTO: APLICACIÓN DE LA TEORÍA DE ALEXY EN EL RE 845.779

Fausto Santos de Morais ${ }^{1}$ Jose Carlos Kraemer Bortoloti ${ }^{2}$

Resumo: A pretensão de correção é o pano de fundo que permite decidir os problemas jurídicos (mediante juízos de subsunção e ponderação) e apresentar a justificativa racional que ateste a legitimidade da decisão judicial. Esta hipótese de pesquisa é desenvolvida numa abordagem hipotéticodedutiva, pelo método fenomenológico-argumentativo e com base na revisão bibliográfica, objetivando apresentar a pretensão de correção e a sua influência para uma razão institucionalizada, bem como a referência desses conceitos para o exercício da argumentação jurídica. Tal pesquisa se justifica tanto pela exigência constitucional de fundamentação das decisões

1 Doutor em Direito Público pela UNISINOS/RS. Docente do Programa Pós-Graduação em Direito da Faculdade Meridional (PPGD/IMED/RS). Pesquisador com apoio da Fundação Meridional. Advogado. E-mail: faustosmorais@gmail.com. Lattes:_http://lattes.cnpq. $\mathrm{br} / 2028518764749733$.

2 Doutor em Direito pela UNESA/RJ, com período de Doutoramento Sanduíche pela Universidade de Lisboa, Portugal. Professor da Escola de Direito da Faculdade Meridional - IMED/RS. Advogado. E-mail: jose.bortoloti@imed.edu.br, Lattes: http://lattes.cnpq. br/4437137331139098. 
judiciais (artigo 93, IX da CRFB) quanto pela necessidade de desmitificação do discurso do princípio da proporcionalidade, para que se conceda a devida atenção à razão institucionalizada e à argumentação jurídica como forma de legitimação do exercício da jurisdição constitucional.

Palavras-chave: Direitos Fundamentais. Princípio da proporcionalidade. Argumentação jurídica.

Abstract: The claim of correctness constitutes a background that makes it possible to decide on legal problems (through subsumption and deliberation) and to show a rational justification that attests to the legitimacy of the judicial decision. This hypothesis was developed within a hypothetical deductive approach, through the argumentative phenomenological method, and using a bibliographical review, aiming to show the claim of correctness and its influence on an institutionalized reason, as well as on legal argumentation practice. The importance of this research lies in the constitutional requirement of a justified decision (article 93, IX CRFB), and in the attempt to demystify the discourse of the principle of proportionality, in order to pay the due attention to institutionalized reason and legal argumentation, as a form of legitimizing the exercise of constitutional judicial review.

Keywords: Constitutional Rights. Principal of Proportionality. Legal Argumentation.

Resumen: La pretensión de la corrección es el telón que permite decidir los problemas jurídicos (mediante juicios de subsunción y de ponderación) y presentar la justificación racional que pruebe la legitimidad de la decisión judicial. Esta hipótesis de investigación se desarrolla con un abordaje hipotético deductivo, a través del método fenomenológico argumentativo y con base en la revisión bibliográfica, con el objetivo de presentar la pretensión de corrección y su influencia para una razón institucionalizada, así como la referencia de esos conceptos para el ejercicio de la argumentación jurídica. Tal investigación se justifica tanto por la exigencia constitucional de fundamentación de las decisiones judiciales 
(artículo 93, IX de la CRFB) como por la necesidad de desmitificación del discurso del principio de la proporcionalidad, para que se conceda la atención debida a la razón institucionalizada y a la argumentación jurídica como forma de legitimación del ejercicio de la jurisdicción constitucional.

Palabras clave: Derechos Fundamentales. Principio de la proporcionalidad. Argumentación jurídica.

INTRODUÇÃO

autoridade judiciária competente pela jurisdição constitucional
vem se destacando há algum tempo por decidir os problemas
com a adoção do discurso do princípio da proporcionalidade.
Esse discurso, via de regra, pressupõe o debate entre normas de direitos fundamentais e a colisão entre a contraposição de princípios jurídicos derivados delas.

De olho no Supremo Tribunal Federal pode-se ilustrar a adoção do discurso no julgamento do caso Ellwanger (HC 82.424/RS), Lei da Ficha Limpa (ADC 29/ DF, ADC 30/DF e ADI 4.578/DF), Pesquisa nas células-tronco embrionárias (ADI 3.510/DF), Demarcação da Raposa do Sol (Pet 3.388/RO), Liberdade de expressão no caso das biografias não autorizadas (ADI 4.815) e, mais recentemente, no voto do Min Gilmar Mendes quanto à posse de drogas para consumo próprio (RE 635.659/SP).

Uma questão comum transita entre o discurso dessas decisões, qual seja: como se pode aferir a validade das decisões judiciais? Em 1973 foi proferida decisão pelo Bundesverfaßungsgericht, BVerfG E 34, 269 (287), estabelecendo que a validade de uma decisão judicial estaria condicionada ao seu apoio em argumentos racionais. Assumindo essa questão como objeto de estudo, Robert Alexy desenvolveu e publicou a Teoria da Argumentação Jurídica (Theorie der juristischen Argumentation, 1978).

Essa teoria tratava das exigências para a argumentação racional das decisões judiciais, especialmente, para a justificação daquelas decisões cuja conclusão 
obtida se apoiasse num processo de dedução por premissas. Essas premissas, por sua vez, implicavam juízos de valor cuja fonte principal, mas não necessária, era o direito positivo.

Robert Alexy publica no ano de 1985 a Teoria dos Direitos Fundamentais (Theorie der Grundrechte). Embora esta obra seja reconhecida por temáticas como a estrutura das normas constitucionais como regras e princípios, a máxima da proporcionalidade e a ponderação, entende-se que dentre elas, a mais relevante seja aquela que discorre acerca da correta justificação referida a direitos fundamentais. Na obra esse esforço é denominado como: a base da argumentação no âmbito dos direitos fundamentais.

A base a que se refere Alexy seria a relação entre pretensão de correção e argumentação jurídica, mais precisamente, a relação entre as decisões judiciais que usam juízos de valor (subsunção e/ou ponderação) e a sua justificação racional. Este será o tema desenvolvido.

Sustenta-se como hipótese de trabalho que a pretensão de correção é o pano de fundo que permite decidir os problemas jurídicos (mediante juízos de subsunção e ponderação) e apresentar a justificativa racional que ateste a legitimidade da decisão judicial. Essa seria a institucionalização da razão.

Tal hipótese encontra sustentação nas seguintes questões, que devem ser explicitadas: a) a influência de Habermas para a concepção da pretensão de correção e para os pressupostos da argumentação jurídica; b) a característica da argumentação jurídica como uma razão institucionalizada, o que será apresentado na condição do caso especial (Sonderfallthese); e, c) a exemplificação da aplicação da teoria de Alexy no RE 845.779.

Com base na pesquisa de revisão bibliográfica, abordagem hipotéticodedutiva e método fenomenológico-argumentativo, o presente trabalho objetiva apresentar a pretensão de correção e a sua influência para uma razão institucionalizada, bem como a referência desses conceitos para o exercício da argumentação jurídica.

Tal pesquisa se justifica tanto pela exigência constitucional de fundamentação das decisões judiciais (artigo 93, IX da CRFB) - o que equivaleria à decisão do 
Bundesverfaßungsgericht supracitada - quanto pela necessidade de desmitificação do discurso do princípio da proporcionalidade, para que se reconheça a devida atenção à razão institucionalizada e a argumentação jurídica como forma de legitimação do exercício da jurisdição constitucional.

\section{PRESSUPOSTOS À TEORIA DA ARGUMENTAÇÃO JURÍDICA DE} ROBERT ALEXY

Ao iniciar essa seção, um esclarecimento preliminar se mostra necessário, qual seja: Robert Alexy funda a sua noção de pretensão de correção do Direito numa correspondência jurídica à noção de pretensão de validade-verdade dos juízos emitidos em proposições empíricas de Habermas 3 . Portanto, aquilo que Alexy vai chamar de "Esboço de uma teoria do discurso prático racional geral" é o conjunto de análises feitas na Filosofia da Linguagem pragmáticotranscendental de Habermas. Essa reconstrução envolve analisar regras e formas de argumentos hábeis para a fundamentação racional das proposições empírico-teóricas e práticas ${ }^{4}$.

Assim, as questões atinentes à validade-verdade de uma proposição empírica (ou prática) somente poderiam ser constatadas mediante a teoria consensual criada por Habermas. A busca do consenso implicaria um avanço sobre a verdade (validade) como característica implícita à lógica da verdade proposicional, demasiadamente formal. Ou seja, a verdade de uma proposição não poderia ser verificada tão somente entre a relação entre o enunciado e o objeto. Pois essa questão teria dois efeitos problemáticos: primeiro, não haveria referência à correção da relação entre o enunciado e o objeto5; segundo, a linguagem não

3 ALEXY, Robert. Teoria da argumentação jurídica: a teoria do discurso racional como teoria da fundamentação jurídica. Trad. Zilda Hutchinson Schild Silva. 2. ed. São Paulo: Landy Editora, 2005, p. 118. O próprio Habermas aponta para a possibilidade de o discurso prático postular a tematização de pretensões de correção normativa, permitindo que, discursivamente, se examine hipoteticamente a condição de determinada norma de ação que pode ser entendida como justificada de modo imparcial. Cf. HABERMAS, Jürgen. Teoria do agir comunicativo. Tradução Paulo Astor Soethe. São Paulo: Editora WMF Martins Fontes, 2012, v. 1, p. 50.

4 ALEXY, Teoria da argumentação jurídica. p. 181.

5 Isso porque, para se pleitear a correção de um enunciado, se mostra necessário pressupor certo objetivismo na relação entre aquilo enunciado e a sua expectativa intersubjetiva. Nesse sentido, Habermas vai dizer que "as condições de validade das exteriorizações sim- 
estaria sendo considerada no seu nível pragmático, deixando de ser constituidora da experiência que se tem com o mundo ${ }^{6}$.

A proposta de Habermas seria colocar em um agir comunicativo as pretensões de validade problemáticas, reconhecendo como racional aquelas que pudessem alcançar o consentimento dos demais envolvidos com o argumento que motive e/ ou convença os demais participantes no discurso ${ }^{7}$. Consequentemente, o âmbito discursivo tratado por Habermas envolve a disputa pelo melhor argumento sobre a validade das proposições afirmadas, devendo prevalecer aquela melhor fundamentada. Portanto, sempre que se falasse algo (ou emitisse um juízo de valor), a validade dessa asserção implicaria a satisfação de sua fundamentação.

O âmbito discursivo para fundamentar as proposições estaria marcado pela sua estrutura lógico-argumentativa orientada ao nível da pragmática. Toda a argumentação poderia ser explicada de maneira formal e lógica (o que envolveria a discussão de questões analítico-semânticas) e pragmática (o pressuposto contextual das proposições). Enfrentando esse desafio, Habermas utiliza-se das formas de argumentos apresentadas por Toulmin ${ }^{9}$, contudo limitadas ao âmbito

bólicas remetem a um saber fundamental partilhado intersubjetivamente pela comunidade de comunicação". Cf. HABERMAS, Teoria do agir comunicativo. p. 40-41. Ainda, "em contextos de ação comunicativa, só pode ser considerada imputável a pessoa que, como participante de uma comunidade de comunicação, seja capaz de orientar seu agir segundo pretensões de validade intersubjetivamente reconhecidas." Cf. HABERMAS, Teoria do agir comunicativo. p. 43.

6 Exaltar-se-ia o caráter linguístico comunicativo da razão. Como afirma Habermas, "(com o) ponto de partida o emprego comunicativo do saber proposicional em ações de fala, tomamos uma decisão prévia em favor de outro conceito de racionalidade, filiado a noções mais antigas de logos. Esse conceito de racionalidade comunicativa traz consigo conotações que, no fundo, retrocedem à experiência central da força espontaneamente unitiva e geradora do consenso própria à fala argumentativa, em que diversos participantes superam suas concepções inicialmente subjetivas para então, graças à concordância de convicções racionalmente motivadas, assegurar-se ao mesmo tempo da unidade do mundo objetivo e da intersubjetividade de seu contexto vital." Cf. HABERMAS, Teoria do agir comunicativo. p. 35-36.

7 Para Habermas argumentação é "o tipo de discurso em que os participantes tematizam pretensões de validade controversas e procuram resolvê-las ou criticá-las com argumentos. Um argumento contém razões que se ligam sistematicamente à pretensão de validade de uma exteriorização problemática. A "força" de um argumento mede-se, em dado contexto, pela acuidade das razões; esta se revela, entre outras coisas, pelo fato de o argumento convencer ou não os participantes de um discurso, ou seja, de o argumento ser capaz de motivá-los, ou não, a dar assentimento à respectiva pretensão de validade". Cf. HABERMAS, Teoria do agir comunicativo. p. 48.

8 Alexy vai chamar isso de regra geral da fundamentação. Cf. ALEXY, Teoria da argumentação jurídica. p. 142.

9 ALEXY, Teoria da argumentação jurídica. p. 127. A estrutura do argumento ou seu elemento formal poderia ser representado por dados (D) que sustentam uma conclusão (C), 
analítico-semântico. Para além da forma, seria necessário buscar nos elementos materiais da argumentação as razões necessárias para o consenso e, portanto, validade, fundamentação, das proposições. Esse conhecimento seria possível somente numa postura pragmático-transcendental ${ }^{10}$.

Essa condição material derivaria da possibilidade de consenso entre os falantes. Tal resultado exigiria uma série de regras que deveriam ser satisfeitas contrafaticamente, permitindo que a obtenção de consenso sobre a fundamentação de determinadas proposições e suas pretensões de validade se dessem de maneira imparcial. Isto é, que a participação dos falantes fosse garantida mediante a livre participação dos interessados. Isso ficou conhecido como a situação ideal de fala ${ }^{11}$. Dessa maneira, todos os falantes teriam direitos iguais, isentos de coerções sobre a sua participação, algo que deveria ser pressuposto em qualquer âmbito discursivo ${ }^{12}$.

Um exemplo privilegiado da teoria discursiva de Habermas seria o desenvolvimento de procedimentos democráticos na formação da legislação como expressão da formação da vontade $\operatorname{popular}^{13}$. Ou seja, o princípio democrático

valendo-se de regras (W), sendo possível apresentar razões para essas regras mediante uma base de conhecimentos (backing)(B). Especula-se que as inferências valorativas, no plano analítico da linguagem, envolveriam discussões a partir das regras (W) que certificam a dedução entre os dados (D) e a conclusão (D).

10 ALEXY, Teoria da argumentação jurídica. p. 137: "[...] transcendental na medida em que as regras podem ser fundamentadas mostrando-se que sua validade é condição de possibilidade da comunicação linguística. É pragmática porque essas regras são regras do discurso que não lidam exclusivamente com a sintaxe ou a semântica, mas vão além disso para regular a relação dos falantes com suas próprias manifestações".

11 ALEXY, Teoria da argumentação jurídica. p. 130. Atienza vai dizer que a situação ideal de fala seriam as condições de liberdade e simetria entre os participantes do discurso que permitiriam um consenso sobre a verdade de preposições ou correção de normas. Cf. ATIENZA, Manuel. As razões do Direito: Teorias da argumentação jurídica. Tradução Maria Cristina Guimarães Cupertino. 3. ed. São Paulo: Landy, 2003. p. 163.

12 ALEXY, Teoria da argumentação jurídica. p. 130. Alexy vai dizer que da exigência de simetria decorreriam quaro classes de atos de fala que integrariam a situação ideal de fala, quais sejam: 1) Todos os potenciais participantes teriam a mesma oportunidade, sendoIhes permitido, a qualquer momento entrar no discurso, apresentando razões, réplicas, perguntas e respostas; 2) Todos os participantes podem realizar interpretações, asserções, recomendações, explicações, justificações e problematizações, fundamentar ou contestar pretensões de validade, cuja opinião deve ser tematizada e criticada; 3) Só se admite os falantes que tem a mesma capacidade de expressar opiniões, sentimentos e expressões; 4) Só se admite os falantes que tem as mesmas possibilidades de ordenar e opor-se, permitir e proibir, prometer e retirar promessas.

13 Habermas vai afirmar, assim, que "a legitimidade do direito apoia-se, em última instância, num arranjo comunicativo: enquanto participantes de discursos racionais, os parceiros do 
reuniria os elementos necessários para que fosse possível obter um consenso sobre determinados assuntos, colocando a deliberação diante dum procedimento de argumentação e a fundamentação diante de todos os potenciais afetados. A construção democrática do Direito, como expressão da soberania popular, permitiria a pressuposição do consenso fundamentada nas normas jurídicas, dotando a legalidade de legitimidade. A capacidade de autolegislação dos cidadãos através da "institucionalização jurídica de condições para um exercício discursivo da autonomia política"14 garantiria a série de requisitos exigidos para a argumentação livre e simétrica ${ }^{15}$ entre os participantes potencialmente atingidos pela norma. Pode-se entender, assim, que a formação democrática do Direito, considerando-a como o Princípio da Democracia ${ }^{16}$, acabaria sendo realizada mediante o Princípio Discursivo. Esses dois princípios integrariam um âmbito democrático do Direito.

O resultado seria um discurso democrático universal cuja função sistêmica estaria na justificação ou na fundamentação a priori das normas do Direito Positivo via um procedimento que garantia a participação e a consideração de todos os interessados ${ }^{17}$ no processo legislativo. Pensando na aplicação do direito devem poder examinar se uma norma controvertida encontra ou poderia encontrar o assentimento de todos os possíveis atingidos. [...] a co-originariedade da autonomia privada e pública somente se mostra, quando conseguimos decifrar o modelo a autolegislação através da teoria do discurso." Cf. HABERMAS, Jürgen. Direito e democracia: entre facticidade e validade. Trad. Flávio Beno Siebeneichler. 2. ed. Rio de Janeiro: Tempo Brasileiro, 2003. v.1., p. 138.

14 Cf. HABERMAS, Direito e democracia. p. 158.

15 Cf. HABERMAS, Direito e democracia. p. 158.

16 O Princípio Democrático teria uma função de assegurar a validade do Direito Positivo mediante a determinação de um procedimento de normatização legítima do Direito. Cf. HABERMAS, Direito e democracia. p. 158.

17 Günther suporta o desenvolvimento do Princípio da Universalização como apto a legitimar a aplicação do Direito Positivo a todos os destinatários e em todas as situações. Cf. GÜNTHER, Klaus. Teoria da argumentação no Direito e na Moral: justificação e aplicação. Tradução Cláudio Molz. São Paulo: Landy Editora, 2004, p.58. Essa seria a universalização ou generalização promovida pelo princípio do Discurso de Habermas. A tese de Günther está fundada no Princípio moral da Universalização - "U", como fundamento necessário de qualquer tipo de argumentação (representada no meio científico pelo princípio da não contradição). O problema do Direito Positivo, nesse sentido, seria que a realização do princípio "U" seria realizado precariamente diante do conhecimento e tempo limitado dos participantes no discurso. Assim, esse nível de justificação a priori somente alcançaria o princípio "U" quando considerasse a dimensão de aplicação concreta. Portanto, quando os elementos concretos também fossem conhecidos - em que todos os interesses dos destinatários e das situações efetivamente seriam conhecidos, a validade da norma a priori poderia ser colocada em xeque diante do fundamento máximo da argumentação: o princípio "U". 
Direito, essas normas ganhariam a condição de Discursos de Fundamentação das normas aplicadas aos casos pelo Poder Judiciário. Aliás, cabe aqui referir que tanto Habermas quanto Günther advogam a possibilidade do Poder Judiciário determinar a validade, ou melhor, a não validade da norma mediante a dimensão de aplicação normativa. Isso porque poderiam as condições de interesses do destinatário concreto e a situação específica exigir revisão da norma a priori. Nesse sentido, o discurso de fundamentação (a priori) ganharia densidade normativa pelo discurso de justificação ${ }^{18}$.

Embora Alexy assuma grande parte dos pressupostos da Teoria do Discurso de Habermas, a sua distinção poderia estar em duas questões. Primeira, a Teoria da Argumentação Jurídica de Robert Alexy procura indicar uma teoria consensual sobre a fundamentação racional (e, portanto, legítima) dos direitos fundamentais. Ao fazer isso, não estaria preocupado em justificar epistemologicamente a função mediadora do Direito para uma teoria social ${ }^{19}$, mas indicar como a pretensão de correção poderia ser alcançada no Direito. Segundo, a fundamentação racional do Direito não estaria isenta de Discursos de Fundamentação. Consequentemente, a Teoria da Argumentação Jurídica proposta por Robert Alexy não se resignaria apenas no espaço da adequação, mas também poderia colocar em questionamento o próprio discurso de fundamentação produzido pelo Poder Legislativo. O resultado seria: num estado constitucional o Poder Judiciário não estaria restrito ao simples ato de aplicação do Direito, mas à sua própria avaliação argumentativa da sua fundamentação in abstrato 20 .

18 Entende-se que a tese de Habermas quanto à complementação entre Validade-Facticidade encontra a sua correspondência com a noção de Discurso de Fundamentação - Justificação. Nesse sentido ambos os autores admitem a necessidade de adequação normativa do Direito Positivo ao caso concreto. É essa a interpretação dada por Luiz Moreira. Cf. MOREIRA, Luiz. Introdução. In: GÜNTHER, Klaus. Teoria da argumentação no Direito e na Moral: justificação e aplicação. Tradução Cláudio Molz. São Paulo: Landy Editora, 2004.

19 O que em Habermas assume força principal diante da tensão produtiva entre democracia e direitos fundamentais, facticidade e validade.

20 Quer dizer, poderia o Poder Judiciário analisar a pretensão de correção das normas legislativas, valendo-se, para tanto, da Teoria da Argumentação Jurídica proposta por Alexy. Nesse sentido, Alexy afirma: "Meu argumento principal é que cada discurso de aplicação abarca um discurso de fundamentação. Isso vale, em todo o caso, então quando se persevera em uma prática de decisão universalista. Abandoná-la, significaria renunciar a uma das exigências mais importantes da racionalidade prática. Com isso, simultaneamente, está dito que a distinção entre a fundamentação e a aplicação de uma norma pode contribuir somente pouco para o problema, no estado constitucional democrático tão central, da delimitação das competências do legislativo daquelas do poder judicial". Cf. ALEXY, Robert. Prefácio. 
É por isso que Alexy procura aprofundar os requisitos necessários para uma argumentação jurídica que busca ir além da proposta incipiente nesse campo indicada por Habermas. Logo, no procedimento discursivo visando ao Direito, Alexy se vale do discurso prático geral, identificando as regras e as formas exigidas por ele que também deveriam ser consideradas pelo discurso jurídico. Sendo assim, qualquer discurso que visa à fundamentação pelo consenso deveria observar formas e regras sobre: a) fundamentais; b) da razão; c) carga da argumentação; d) formas de argumento; e) regras da fundamentação; e f) regras de transição ${ }^{21}$.

Interessa ressaltar o posicionamento de Alexy quanto à incapacidade das regras e das formas do discurso prático racional, bem como jurídico, estipularem as premissas pelas quais o esforço argumentativo deveria ser desenvolvido. Deixando as premissas de lado e concentrando-se em regras procedimentais que orientariam o discurso jurídico, garantir-se-ia o desenvolvimento argumentativo democrático, permitindo a consideração de diferentes concepções normativas ${ }^{22}$.

Embora diga Alexy que as regras de discurso não possam determinar os resultados das questões jurídicas, elas continuariam servindo, eis que cumpririam importantes funções no Direito, quais sejam: explicação da pretensão de correção, referência para correção dos enunciados normativos, crítica a fundamentações não racionais ${ }^{23}$. Ainda, para a Ciência do Direito, as regras do discurso teriam validade, inclusive, para dizer que a decisão é justa ${ }^{24}$.

Uma das necessidades que levou Alexy a pensar a teoria do discurso jurídico foia existência de um procedimento de fundamentação, mediante argumentos, como

In: ALEXY, Robert. Direito, Razão, Discurso: estudos para a filosofia do direito. Tradutor Luís Afonso Heck. Porto Alegre: Livraria do Advogado Editora, 2010, p. 11. Alexy vai dizer que a aplicação do Direito determina a precisão, a modificação ou a criação das normas, o que não abarcaria apenas discursos de justificação, mas exigiriam, também, discursos de fundamentação normativa. É dizer que nesses casos o âmbito da argumentação jurídica não poderia ser reduzido à necessidade de justificação do universal ao particular. Cf. ALEXY, Robert. Fundamentação de normas e aplicação de normas. In: ALEXY, Robert. Direito, Razão, Discurso: estudos para a filosofia do direito. Tradutor Luís Afonso Heck. Porto Alegre: Livraria do Advogado Editora, 2010, p. 59

21 ALEXY, Teoria da argumentação jurídica. p. 283-285.

22 ALEXY, Fundamentação de normas e aplicação de normas. p. 47.

23 ALEXY, Fundamentação de normas e aplicação de normas. p. 47.

24 ALEXY, Fundamentação de normas e aplicação de normas. p. 48. 
caminho viável para dar validade à pretensão de correção. Assim, por exemplo, a pretensão de correção tanto na atividade legislativa como adjudicatória teria a sua validade testada mediante um procedimento discursivo ${ }^{25}$.

Essa noção procedimental assumida por Alexy envolveria a possibilidade do embate de razões ou argumentos que seguiriam determinadas regras, sejam elas para dotar a discussão do adjetivo de racional ${ }^{26}$, sejam elas regras específicas de determinado procedimento jurídico, por exemplo. As regras que regulariam a racionalidade da discussão são denominadas por Alexy como determinantes da argumentação prática geral, estabelecendo condições de liberdade e igualdade entre os participantes do processo argumentativo. Embora tais regras pudessem ter a sua realização apenas de forma ideal, serviriam, na prática, como condições que poderiam ser concretizadas aproximadamente. Mesmo assim, com essa deficiência, não perderiam a qualidade de indicar condições de liberdade e igualdade entre os participantes do discurso.

\section{A ARGUMENTAÇÃO JURÍDICA COMO CASO ESPECIAL}

(SONDERFALLTHESE)

A influência da filosofia de Habermas para um modelo teórico racional, discursivo e procedimental seria levar à realização jurídica por Alexy com a tese do caso especial (Sonderfallthese).

Assim, entende Alexy que a argumentação jurídica destinada à discussão de questões práticas (ordenado, proibido e permitido) seria um caso especial de argumentação prática geral. Isto é, a argumentação jurídica, além de envolver as mesmas regras do discurso prático geral, exigiria limitações próprias para que se pudesse considerar determinada pretensão de correção como juridicamente válida.

Em outras palavras, o Direito instituiria limitações relativas ao conteúdo que poderia ser admitido como passível de discussão, bem como ao âmbito procedimental em que a argumentação deveria dar-se. Essas limitações deveriam 25 ALEXY, Institucionalização da razão. p. 25.

26 ALEXY, Institucionalização da razão. p. 26. 
ser consideradas como racionais porque respeitariam a universalidade, na medida em que delimitariam de igual forma a liberdade de participação argumentativa dos interessados.

Dessa maneira, a verificação da validade ou da pretensão de correção de diferentes interpretações jurídicas estariam fundamentadas quando fossem apresentadas razões resistentes ao procedimento jurídico. Assim, o procedimento jurídico como âmbito de desenvolvimento discursivo teria a finalidade de certificar a pretensão de correção ${ }^{27}$.

A existência de um procedimento discursivo em que se desenvolveria a argumentação jurídica teria a vantagem de reconhecer a pretensão de correção, entretanto não teria o poder de indicar apenas uma alternativa interpretativa. Isto é, para Alexy, o caminho indicado pelo procedimento discursivo delimitaria o âmbito decisório, contudo não teria a força para determinar apenas uma resposta. Haveria, neste caso, mais de uma resposta considerada discursivamente, visto que atenderia às mais diversas condições racionais como: lógicas, de participação, carga argumentativa, universalidade ${ }^{28}$.

A pluralidade de possibilidades interpretativas seria um elemento ínsito à condição discursiva-racional. A grande característica que diferenciaria o discurso jurídico seria a pergunta pela pretensão de correção da decisão de acordo com a ordem jurídica vigente. Ou, de forma mais simples, surgiria a pergunta sobre a correção da interpretação, norma de direito fundamental atribuída ou proposição jurídica diante do sistema jurídico vigente ${ }^{29}$.

A pretensão de correção frente ao sistema jurídico vigente reduziria o âmbito das possibilidades discursivas proveniente do espaço de discussão prático geral, transformando aquilo que inicialmente seria considerado como discursivamente possível $^{30}$ naquilo juridicamente permitido de se discutir. Teriam essa função as regras, os princípios e os procedimentos jurídicos ${ }^{31}$.

27 ALEXY, Robert. La idea de una teoría procesal de la argumentación jurídica. In: ALEXY, Robert. Derecho y razón práctica. México: Distribuciones Fontamara, 1993, p.60.

28 ALEXY, La idea de una teoría procesal de la argumentación jurídica. p. 63.

29 ALEXY, Robert. Posfácio. In: ALEXY, Robert. Teoria da argumentação jurídica: a teoria do discurso racional como teoria da fundamentação jurídica. Trad. Zilda Hutchinson Schild Silva. 2. ed. São Paulo: Landy Editora, 2005, p. 310.

30 ALEXY, La idea de una teoría procesal de la argumentación jurídica. p. 70.

31 ALEXY, La idea de una teoría procesal de la argumentación jurídica. p. 69. 
Alexy reconhece a incapacidade da discussão racional para resolução de problemas práticos, com a definição da ação obrigatória, proibida e permitida. O discurso prático geral não conseguiria resolver esses problemas, visto que as suas regras que conferem racionalidade necessitam ser complementadas pelas regras próprias do discurso jurídico. Somente as regras do discurso jurídico seriam capazes de pôr fim na discussão quanto à pretensão de correção, dizendo, ao final, aquilo que é obrigado, proibido e permitido.

Para tanto, a argumentação considerada no discurso jurídico serviria para reconhecer o dever-ser de determinadas ações, com base em procedimentos jurídicos estruturados. Essa estrutura procedimental poderia ser encontrada na criação de normas jurídicas, o que, especula-se, poderia ser chamado de procedimento discursivo para criação de leis.

No sistema jurídico romano-germânico, matriz do sistema jurídico alemão e brasileiro, o procedimento legislativo é responsável pela produção de leis como fonte primordial do estabelecimento de condutas. O dever-ser é estabelecido, via de regra, através do procedimento legislativo. Assim, quando se diz que alguém possui determinado Direito, o primeiro recurso discursivo é apontar a referência daquela norma positiva no texto legislativo.

Mesmo assim, embora o discurso jurídico reverencie a importância das leis, as razões para determinadas ações nem sempre decorrem exclusivamente do texto legal. Boa parte das vezes as partes discutem sobre seus direitos, fazendo referência a outras razões como a jurisprudência ou a doutrina. Dir-se-ia: "tenho direito conforme a jurisprudência vem consagrando" ou "conforme a doutrina da responsabilidade objetiva, tenho direito...". Esses âmbitos de discussão seriam prova de que o discurso jurídico, mesmo limitado pela noção de lei, ainda envolveria controvérsias.

O procedimento ou processo judicial surge como âmbito conclusivo sobre as controvérsias quanto ao dever-ser, indicando a ação devida juridicamente ${ }^{32}$. Ou seja, mesmo se reconhecendo a delimitação progressiva do âmbito de discussão 32 ALEXY, La idea de una teoria procesal de la argumentación jurídica. p. 70; ALEXY, Teoria dos Direitos Fundamentais. p. 550. 
sobre que conduta deve-se praticar, respectivamente, através da lei, jurisprudência e doutrina, apenas o processo judicial seria capaz de dizer, concretamente, o que deveria ser feito. Logo, somente através do processo judicial, como uma sucessão de ritos, reconhece-se a satisfação das regras do discurso prático geral e do discurso jurídico, há, dessa forma, a definição sobre que conduta deve ser exigida ${ }^{33}$.

No entendimento de Alexy, o discurso jurídico poderia ser considerado de estrutura dupla, isto é, teria elementos que envolveriam a lei, dos precedentes e da dogmática; ao mesmo tempo em que exigiria elementos próprios de um discurso prático geral. ${ }^{34} \mathrm{O}$ discurso jurídico seria menos vago que o discurso prático geral, mas, mesmo assim, não poderia resolver os problemas sociais sem um procedimento complementar fornecido através do processo judicial. Em outras palavras, a efetiva forma de resolução dos conflitos sociais efetivamente se daria mediante um procedimento judicial ou processo judicial, pelo qual não apenas se decidiria, mas também se argumentaria, fundamentando racionalmente essa decisão. A racionalidade da decisão seria conferida pelo fato de a decisão satisfazer as regras estipuladas nos procedimentos, presumindose, dessa maneira, a sua fundamentação ${ }^{35}$.

Não se pode esquecer, contudo, de um elemento de importante função tanto para o discurso prático geral quanto para o discurso jurídico, qual seja: o Princípio da Universalização. Na lógica, ele estaria representado pela não contradição. Na ética (aplicável ao Direito), pela exigência de imparcialidade como igual consideração aos interesses e às condições concretas em todas as situações. Esse seria o fundamento argumentativo procedimental da universalidade ${ }^{36}$ - duma moral pós-convencional, aplicável às questões práticas, inclusive ao Direito. Numa especulação, esse fundamento do discurso prático geral atravessaria o discurso jurídico.

Indicada a relação entre o discurso prático geral e o discurso jurídico, Alexy procura apresentar todas as regras necessárias para que a decisão judicial pudesse

33 ALEXY, Teoria dos Direitos Fundamentais. p. 548.

34 ALEXY, Teoria dos Direitos Fundamentais. p. 550.

35 ALEXY, Teoria dos Direitos Fundamentais. p. 551.

36 Cf. DUARTE, Écio Oto Ramos. Teoria do discurso e correção normativa do direito: aproximação à metodologia discursiva do direito. 2. ed. São Paulo: Landy Editora, 2004, p. 202. 
obter a qualificação de racional. Para tanto, indica o autor vinte e oito regras na integração entre o discurso prático geral e o jurídico. Essas regras envolvem a fundamentação sob duas perspectivas. Alexy vai dizer, na verdade, que existiriam duas formas de justificação (como fundamentação racional) presentes na argumentação jurídica, a interna e externa.

A justificação interna seria a necessidade de se apresentar a fundamentação entre o resultado normativo (norma) e a proposição jurídica positivada no texto constitucional, por exemplo. Ela procuraria justificar a validade do silogismo jurídico, apresentando a premissa maior (proposição jurídica), os fatos e a conclusão (norma). Vale destacar que a justificação interna não estaria limitada à demonstração somente das proposições jurídicas textualmente presentes na constituição (ou lei), mas serviria também para indicar a ligação entre uma possível norma de direito fundamental atribuída (ou lei de colisão, como resultado da ponderação), caso concreto e conclusão normativa ${ }^{37}$. Isto é, as regras de justificação interna serviriam para apresentar como o enunciado jurídico, texto ou interpretação atribuída a ele, estaria conectado aos fatos e à conclusão.

As principais regras que orientariam a justificação interna envolveriam a necessidade de fundamentação da decisão (interpretação) a partir de uma norma de cunho universal, apresentando, passo a passo, a cadeia de proposições que ligam a decisão à norma. Assim, a justificação interna teria a sua qualidade vinculada à indicação do maior número de proposições intermediárias entre a norma universal utilizada como premissa inicial e a conclusão ${ }^{38} 39$.

A racionalidade exigida pelas regras de justificação interna permitiria apresentar como a norma jurídica de cunho universal - proposição jurídica ou interpretação dela - se tornaria paulatinamente concreta até surgir ou corresponder às condições fáticas do caso concreto. Nesse procedimento de justificação interna não teria importância se a premissa maior fosse obtida no Direito positivo (texto)

37 ALEXY, Teoria da argumentação jurídica. p. 218-219.

38 ALEXY, Teoria dos Direitos Fundamentais. p. 219. A questão revela a importância para Alexy do princípio racional de universalidade, sendo ele determinante à argumentação prática geral, tendo a sua ressonância no Direito, para fundamentar a racionalidade do raciocínio jurídico.

39 ALEXY, Teoria dos Direitos Fundamentais. p. 224. 
ou derivaria da construção do intérprete ${ }^{40}$, no caso da norma atribuída ou da lei de colisão. A escolha da premissa maior transcenderia o objetivo da justificação interna, sendo objeto de indagação pela justificação externa.

Especula-se, portanto, a existência de conexão entre as duas formas de justificação indicadas por Alexy. O procedimento de justificação da interpretação jurídica poderia ser classificado em duas etapas distintas, mas interligadas. Primeiro, o intérprete deveria esforçar-se para expor todas as proposições intermediárias envolvidas entre a premissa maior e a conclusão - tarefa da justificação interna. Depois, na segunda etapa, dever-se-ia apresentar a fundamentação da escolha das premissas maiores como objetivo da justificação externa ${ }^{41}$.

Quer dizer, a função da justificação externa seria a fundamentação das premissas iniciais do silogismo jurídico, o que daria caráter de racionalidade à decisão ${ }^{42}$. Pertinente, nesse momento, é lembrar que a construção de normas de direito fundamental atribuídas ou lei de colisão é um produto do relacionamento condicional entre princípios jurídicos, o que importaria na construção de uma proposição jurídica ${ }^{43}$. Tal proposição, por sua vez, seria aplicada ao caso concreto mediante subsunção. É dizer, portanto, que a colisão entre princípios jurídicos, num âmbito ideal do dever-ser máximo de sua ordem, poderia, na realidade, apenas ser obtido aproximadamente na realidade. Essa realização implicaria a construção de uma proposição jurídica aplicável mediante subsunção. Isto é, do conflito entre princípios jurídicos considerados como comandos ideais, chegarse-ia à regra aplicável, mediante subsunção ao caso concreto.

A fundamentação da aplicação dessa regra específica ao caso concreto seria objeto da justificação interna. Por sua vez, ainda restaria a necessidade de justificação da própria regra obtida. Ou seja, como se justificaria a norma de direito fundamental atribuída ou a lei de colisão em si? Para essa questão, a justificação externa serviria.

Portanto, crê-se que a justificação externa procura fundamentar a escolha da premissa inicial, admitindo que esta seja proveniente do Direito positivo 40 ALEXY, Teoria da argumentação jurídica. p. 224.

41 ALEXY, Teoria da argumentação jurídica. p. 224.

42 ALEXY, Teoria da argumentação jurídica. p. 226.

43 Cf. ALEXY, A análise lógica de decisões jurídicas. p. 24. 
(proposição jurídica textual), enunciados empíricos ou outro ${ }^{44}$. Especulando, ainda, parece que quando Alexy indica outra premissa possível além do Direito positivado e dos enunciados empíricos, estaria o autor se referindo à norma de direito fundamental atribuída ou à lei de colisão.

Para Alexy, a justificação externa faria referência a diversos elementos que poderiam fundamentar a utilização de determinada premissa. No sistema jurídico romano-germânico, a principal forma de fundamentar a utilização de determinada premissa estaria na sua indicação como texto positivado legislativamente.

Mesmo assim, não seria possível apenas mediante o textojurídicojustificar todas as premissas iniciais da adjudicação. Como já referido, no caso de indeterminação semântica, dever-se-ia recorrer aos cânones de interpretação, dogmática jurídica e aos precedentes, tanto um quanto os outros teriam a função de reduzir a ambiguidade e a vagueza do texto jurídico ${ }^{45}$. Pela interpretação jurídica, seria possível apelar a razões como o "sentido literal", vontade do legislador, razões sistemáticas e teleológicas ${ }^{46}$.

Contudo, indica Alexy que não seriam apenas os cânones interpretativos que forneceriam razões para justificar a premissa escolhida. Isso porque a valoração desses cânones poderia envolver discussões desenvolvidas na dogmática jurídica, campo em que, entre diversas interpretações, o sentido jurídico seria estabilizado como válido ou inválido, delimitando o seu campo de aplicação, bem como indicando a sua correção diante do sistema jurídico e hipóteses a serem cogitadas em novos $\operatorname{casos}^{47}$.

As razões colhidas na intepretação autêntica também serviriam para auxiliar na fundamentação das premissas judicativas. Ou seja, os precedentes ${ }^{48}$ seriam razões que sustentariam a adoção das premissas maiores à justificação interna. Aqui, vale lembrar a noção que Alexy desenvolve sobre a substancialidade do sistema jurídico e a sua conexão com a moral.

\footnotetext{
44 ALEXY, Teoria da argumentação jurídica. p. 226.

45 Cf. ALEXY, A análise lógica de decisões jurídicas. p. 24.

46 Cf. ALEXY, Teoria da argumentação jurídica. p. 241.

47 Cf. ALEXY, Teoria da argumentação jurídica. p. 257-262.

48 Cf. ALEXY, Teoria da argumentação jurídica. p. 264-267.
} 
O que se quer dizer é que os precedentes servem para indicar uma ordem objetiva relativa entre critérios de valoração (princípios jurídicos ou valores) que deveriam ser tomados como razões que fundamentariam cada decisão. Nesse caso, especula-se que o precedente como construção adjudicatória que expressa a lei de colisão, estipulando determinada regra condicionada de relação entre princípios jurídicos, deveria ser posteriormente compreendido como organização objetiva de valores do sistema jurídico.

Ainda, Alexy vai indicar a existência de outros elementos de justificação externa, como a razão, a empiria ou os argumentos jurídicos especiais ${ }^{49}$, o que, diante da limitação estabelecida pelo discurso jurídico (lei, dogmática e precedentes), parece ter uma função secundária no procedimento de fundamentação, considerando, principalmente, a atribuição que o autor faz à argumentação prática geral.

\section{A PONDERAÇÃO NO RE 845.779/SC: OS ARGUMENTOS DO MIN. LUIS ROBERTO BARROSO}

No final do ano de 2015 o STF iniciou o julgamento do Recurso Extraordinário $\mathrm{n}^{\circ}$ 845.779/SC. A relatoria ficou a encargo do Ministro Luis Roberto Barroso, que proferiu o seu voto na sessão plenária do dia 19 de novembro de 2015. Atualmente o caso está aguardando o pedido de vistas do Ministro Luiz Fux.

O caso envolve a discussão sobre o direito de reparação de danos morais a um transexual que teria sido constrangido por um funcionário de shopping center em Florianópolis (SC) ao tentar utilizar o banheiro feminino.

Frisa-se que o recurso especial chegou até o STF em virtude de ter o Tribunal de Justiça de Santa Catarina negado o direito à indenização por danos morais ao transexual, decidindo o tribunal que a retirada forçada do banheiro feminino deveria ser entendida como mero dissabor. No recurso contra essa decisão, afirmou-se a existência de discriminação, o que geraria o dever de indenizar além de violação ao princípio da dignidade da pessoa humana. ${ }^{50}$

49 Cf. ALEXY, Teoria da argumentação jurídica. p. 226.

50 Discurso esse que ganha uma condição universal pela sua aplicação através das cortes superiores. Cf. STAFFEN, Marcio Ricardo; ARSHAKYAN, Mher. The legal development of the 
O voto do Min. Luis Roberto Barroso servirá de exemplo tanto para a análise dos argumentos empregados na justificação da ponderação, como método utilizado na decisão, quanto para a verificação prática dos teoremas de Alexy sobre o caso especial e sobre os diferentes tipos de argumentos para a fundamentação de uma decisão judicial. Como o primeiro teorema já foi supra apresentado, resta discutir a questão sobre os tipos de argumentos e a relação desses com a decisão apontada.

Assume-se, como pressuposto, que as proposições do voto do Min. Luis Roberto Barroso suportam a criação de uma lei de colisão ${ }^{51}$ mediante a ponderação feita por ele entre o direito ao uso do banheiro feminino por transexual de um lado e o direito à privacidade de outro.

Como é costume nesse tipo de demanda, a decisão não é proferida simplesmente com apoio num material legislativo explícito sobre os direitos e os deveres existentes, mas numa atribuição de sentido que recorre também a outros tipos de elementos.

Em casos assim, exige-se do Poder Judiciário um exercício argumentativo diferenciado para fundamentar as suas decisões, procurando promover uma justificação da ponderação.

Contudo, esse modelo de decisão por ponderação vem enfrentando dois tipos de críticas. Elas são de ordem teórica e prática. Teoricamente a ponderação é questionada em virtude da qualidade epistemológica da sua estrutura argumentativa como racional. ${ }^{52} \mathrm{Na}$ vertente prática, a crítica é dirigida ao emprego dos princípios jurídicos, à retórica ${ }^{53}$ e ao exercício da discricionariedade

notion of human dignity in the constitutional jurisprudence. Revista Brasileira de Direito. v. 12, n. 2, p. 108-126, dez. 2016. ISSN 2238-0604. Disponível em: <https://seer. imed.edu.br /index.php/revistadedireito/article/view/1560>. Acesso em: 14 fev. 2017.

51 A lei de colisão é a representação do juízo de ponderação através de uma proposição do tipo: o direito ao uso do banheiro feminino prepondera sobre o direito de privacidade nas condições fáticas e jurídicas do caso. Cf. ALEXY, Teoria dos Direitos Fundamentais. p. 99.

52 JESTAEDT, Matthias. The Doctrine of Balancing - its Strengths and Weaknesses. In. KLATT, Matthias. (Ed.). Institutionalized Reason. The Jurisprudence of Robert Alexy. Oxford: Oxford University Press, 2012. TSAKYRAKIS, Stavros. Proportionality: An Assault On Human Rights? I-Con. v. 7. n. 3. 2009, p. 468-493. ENDICOTT, Timothy. Proportionality and Incommensurability. In. HUSCROFT, Grant (ed.). Proportionality and the Rule of Law: rights, justification, reasoning. New York: Cambridge University Press, 2014.

53 ATIENZA, Manuel. A voltas com la ponderación. Anales de la Cátedra Francisco Suárez. n. 44. 2010, p. 43-59, p. 50. 
na decisão. ${ }^{54}$ Como o STF vem aplicando a ponderação, entende-se que as duas classes de críticas lhe são passíveis.

Para fins da construção de um esquema para análise da fundamentação nas decisões do STF, adotar-se-á um sistema de categorização dos argumentos utilizados. Como a intenção é discutir o modelo da argumentação jurídica voltada aos direitos fundamentais, adotar-se-á o sistema classificatório empregado por Robert Alexy.

Robert Alexy, na sua Teoria Discursiva do Direito, entende que os argumentos jurídicos podem ser classificados como institucionais e não institucionais. ${ }^{55}$ Esses dois principais tipos de argumentos são encontrados constantemente na fundamentação das decisões judiciais que envolvem na sua controvérsia os direitos fundamentais.

Os argumentos institucionais são aqueles que derivam de uma fonte autoritativa do Direito, tendo como seus principais representantes a legislação os precedentes e a dogmática jurídica consolidada. Os argumentos não institucionais são os tipos de argumentos que não derivam de uma fonte autoritativa, caracterizandose como os argumentos morais, pragmáticos ou éticos. ${ }^{56}$

Os argumentos institucionais geralmente são utilizados para aqueles casos em que se discute a aplicação ou não de determinada regra constituída na legislação ou nos precedentes. Quando a esfera de discussão se aproxima de casos duvidosos ou não previstos, os argumentos não institucionais assumem um papel relevante na fundamentação da decisão. Assim, quando se procura justificar a aplicação do princípio da proporcionalidade em sentido estrito, por exemplo, há uma maior utilização dos argumentos não institucionais, pois as razões empregadas para justificar a ponderação entre diferentes princípios jurídicos se valem de juízos morais, pragmáticos ou éticos.

Para fins da categorização proposta, cabe o esclarecimento dos três tipos de argumentos não institucionais. Portanto: a) os argumentos morais estão relacionados com a resposta à pergunta: o que se deve fazer? b) os argumentos 54 STRECK, Lenio Luiz. Verdade e consenso. Constituição, hermenêutica e teorias discursivas. 4. ed. São Paulo: Saraiva, 2011. ALEXANDER, Larry. Legal Objectivity and the Illusion of Legal Principles. In. KLATT, Matthias. (Ed.). Institutionalized Reason. The Jurisprudence of Robert Alexy. Oxford: Oxford University Press, 2012.

55 Cf. ALEXY, Robert. Direito, Razão, Discurso. Estudos para a filosofia do direito. Trad. Luís Afonso Heck. Porto Alegre: Livraria do Advogado Editora, 2010, p. 73.

56 ALEXY, Robert. Teoria Discursiva do Direito. Rio de Janeiro: Forense Universitária, 2014, p. 319. 
pragmáticos envolvem as relações entre meios e fins ou no conflito entre os fins, definindo-se qual deveria obter maior peso; c) os argumentos éticos procurariam justificar racionalmente os juízos, principalmente diante de valores socialmente aceitos. A definição adota como referência o posicionamento de Alexy. ${ }^{57}$

Vale aqui fazer um esclarecimento. Quando se utilizam os princípios jurídicos como razões para as decisões judiciais, especialmente quando há ponderação, fica mais evidente a relação existente entre o Direito e a Moral, fazendo com que haja um maior emprego dos argumentos não institucionais para a fundamentação da decisão.

No caso sob análise, entendeu o Min. Luis Roberto Barroso haver a necessidade de ponderação entre o direito de uso de banheiro feminino de acesso público por parte da transexual feminina de um lado e de outro o direto de privacidade das mulheres. O quadro a seguir esquematiza a decisão e os seus argumentos:

\begin{tabular}{|l|l|}
\hline Identificação do caso & $\begin{array}{l}\text { RE } 845.779 / S C \\
\text { Uso de banheiro feminino por transexual }\end{array}$ \\
\hline Direitos ponderados & $\begin{array}{l}\text { Direito de uso do banheiro feminino } \\
\text { Direito de privacidade das mulheres }\end{array}$ \\
\hline Lei de colisão & $\begin{array}{l}\text { Direito ao uso do banheiro feminino deve } \\
\text { preponderar sobre o direito de privacidade } \\
\text { das mulheres }\end{array}$ \\
\hline Argumentos não institucionais & i. $\begin{array}{l}\text { Restrição leve à privacidade. } \\
\text { Constrangimento limitado pelo fato das } \\
\text { cabines serem privativas }\end{array}$ \\
(Juízos morais, pragmáticos e éticos). & iii. $\begin{array}{l}\text { Presença de transexual nas áreas comuns do } \\
\text { banheiro geraria apenas um desconforto } \\
\text { Presena de transexual em banheiro } \\
\text { masculino geraria um desconforto maior } \\
\text { Restrição mais intensa ao direito de } \\
\text { igualdade e liberdade }\end{array}$ \\
v. $\begin{array}{l}\text { Estado deve adotar uma postura ativa contra } \\
\text { o preconceito e a intolerância, protegendo } \\
\text { as escolhas existenciais das pessoas em } \\
\text { consonância a sua identidade de gênero }\end{array}$ \\
\hline
\end{tabular}

57 Cf. ALEXY, Robert. Teoria Discursiva do Direito. p. 96. 
Nota-se que a fundamentação da ponderação realizada se estruturou exclusivamente em argumentos não institucionais. O julgador apresenta juízos morais sobre o que seria bom à sociedade (v), juízos pragmáticos ao apresentar as distinções no tratamento dos direitos envolvidos (comparação entre i e iv), bem como juízos éticos quanto ao peso das restrições (ii e iii).

Pode-se induzir que a argumentação jurídica teve como característica determinante valer-se de argumentos não institucionais para fundamentar a ponderação entre diferentes direitos envolvidos. Consequentemente, o âmbito dessa argumentação jurídica não goza do tradicional esquema de fundamentação do raciocínio jurídico. ${ }^{58} \mathrm{Em}$ casos assim, os elementos de justificação externa representados por razões morais, pragmáticas e éticas devem ser o foco da discussão.

De uma maneira geral, os elementos de justificação externa fornecem um código da razão jurídica, mas não seriam critérios últimos para fundamentação das premissas utilizadas nas decisões, nos moldes da apresentada pelo voto na decisão do RE 845.779/SC.

Isso porque, mesmo havendo limitações substanciais impostas pelos elementos de justificação externa até então vistos, a argumentação prática geral figura como discurso prático geral. Seria o discurso prático geral responsável por organizar a relação entre os demais elementos de justificação externa, estabelecendo a relação hierárquica entre eles ${ }^{59}$, o que pode envolver a indicação de premissas adicionais ainda não contempladas ${ }^{60}$.

O envolvimento de premissas adicionais exigiria um ato de valoração do intérprete. É por isso que Alexy vai referir que a lei de colisão implica um ato de valoração que estipula qual princípio jurídico deve prevalecer, naquelas condições, sobre outro. Esse juízo valorativo seria algo ínsito ao sistema jurídico.

58 A teoria da argumentação jurídica desenvolvia por Robert Alexy em 1978 foi idealizada para a justificação racional de juízos legais com base em subsunções, havendo espaço para que se teorize sobre a forma de justificação racional das decisões sobre direitos fundamentais, especialmente, aquelas que utilizam a ponderação. Cf. KLATT, Matthias. (Ed.). Institutionalized Reason. The Jurisprudence of Robert Alexy. Oxford: Oxford University Press. 2012.

59 Cf. ALEXY, Teoria da argumentação jurídica. p. 243.

60 Cf. ALEXY, Teoria da argumentação jurídica. p. 274. 
No caso sob análise, é a lei de colisão em que o juízo ponderativo do Ministro Luis Roberto Barroso pode ser representado.

Não é à toa que Alexy refere que o sistema jurídico orientado à razão prática - que diz o que é obrigado, proibido ou permitido - exigiria um modelo do tipo regra/princípios jurídicos/procedimento ${ }^{61}$. Embora fosse possível construir uma "ordem mole" de valores objetivos do sistema jurídico ${ }^{62}$, sempre se mostraria necessário, diante de um caso concreto, colocar a organização do sistema jurídico contra o seu limite.

Logo, as regras jurídicas e os princípios jurídicos, bem como as leis de colisões representadas em precedentes, não possuiriam a capacidade de abarcar todos os casos possíveis ${ }^{63}$. É nessa hipótese que o procedimento decisório instituído pelo sistema jurídico seria o âmbito pelo qual valorações adicionais seriam incorporadas, cuja validade estaria condicionada à possibilidade de controle racional dos juízos de valor através da sua fundamentabilidade ${ }^{64}$.

Defende Alexy, portanto, que a argumentação jurídica seria um tipo de teoria moral procedimental em que determinadas regras e condições conduziriam - argumentar racional prático ${ }^{65}$, cuja validade implicaria a possibilidade de fundamentação racional das decisões judiciais.

Assim, ao responder sobre a possibilidade de normas atribuídas ao texto jurídico, Alexy desenvolve um arcabouço teórico que interliga a noção dos princípios jurídicos à argumentação jurídica. Sendo os princípios critérios valorativos, cuja ordem deve ser otimizada, surge para o jurista a necessidade de harmonizar diferentes comandos conflitantes, criando, para tanto, a regra de precedência condicionada às condições jurídicas e fáticas de determinado caso concreto.

61 ALEXY, Robert. Sistema jurídico e razão prática. In: ALEXY, Robert. Direito, razão, discurso: estudos para a filosofia do direito. Trad. Luís Afonso Heck. Porto Alegre: Livraria do Advogado Editora, 2010, p. 173.

62 Alexy vai dizer que o sistema jurídico se constitui numa ordem mole por que: (1) estabeleceria condições de primazia, (2) através da lei de colisão, buscando a constate realização dos princípios jurídicos como mandamentos de otimização, determinando (3) primaziasprima facie como cargas de argumentação. Cf. ALEXY, Sistema jurídico e razão prática. p. 171-172.

63 Alexy vai afirmar que o Direito deve ser considerado como um sistema valorativamente aberto. Cf. ALEXY, A análise lógica de decisões jurídicas. p. 27.

64 ALEXY, Sistema jurídico e razão prática. p. 174.

65 ALEXY, Sistema jurídico e razão prática, p. 174. 
Consequentemente, a criação das regras de precedência condicionada estabeleceria uma rede objetiva de valores, instituindo determinada carga argumentativa o que, numa especulação, corresponderia à pretensão de correção plasmada na jurisprudência ${ }^{66}$. Portanto, no caso em que são apresentadas razões não institucionais para sustentar o resultado da ponderação entende ser coerente o posicionamento, diante da teoria de Robert Alexy, de integração dessas razões a uma dimensão em que o Direito é institucionalizado.

\section{CONSIDERAÇÕES FINAIS}

No exercício da jurisdição constitucional, em questões sobre direitos fundamentais, há visível recurso à subsunção e à ponderação como juízos que suportariam o resultado das decisões judicias, sonegando os problemas da justificação (argumentação) racional.

Nesse sentido, mensura-se que o recurso ao princípio da proporcionalidade como referência à ponderação é apenas uma pequena parte do constructo teórico de Robert Alexy. Reportando à tese do caso especial (Sonderfallthese), parece que o emprego do princípio da proporcionalidade, embora possua função importante, desconsidera o seu condicionamento a um exercício argumentativo orientado à razão institucionalizada que incorpora uma determinada pretensão de correção.

Falar em argumentação jurídica para os direitos fundamentais, principalmente no contexto da obra de Robert Alexy, exigiria o reconhecimento de um âmbito discursivo determinado pela pretensão de correção, cuja função principal seria legitimar racionalmente as decisões judiciais.

A questão que se põe pelo exemplo discutido, no entanto, é da hipótese de que na resolução de casos com recurso à ponderação há, nos termos da teoria de Alexy, o privilégio de argumentos fora da dimensão institucional do Direito.

66 Nesse sentido é possível afirmar que a aplicação do princípio da proporcionalidade vem levando a uma expansão dos direitos fundamentais. Cf. MORAIS, Fausto Santos de; ZOLET, Lucas. Constitutional rights expansion and contributions from Robert Alexy's theory / A expansão dos direitos fundamentais e a contribuição teórica de Robert Alexy. Revista Brasileira de Direito. v. 12, n. 2, p. 127-136, dez. 2016. ISSN 2238-0604. Disponível em: <https://seer. imed.edu.br/index.php/revistadedireito/article/view/1505>. Acesso em: 14 fev. 2017. 
O voto do Min. Luis Roberto Barroso no RE 845.779/SC, sobre a indenização à transexual por proibição de uso de banheiro do sexo com o qual se identificava, serve como um exemplo de fundamentação por argumentos não institucionais em virtude da ponderação proposta. Como tal tipo de argumentos foram determinantes para o resultado, retoma-se o questionamento: o exercício discursivo do Direito admite o emprego de argumentos não institucionais como racionais? Sustenta-se positivamente essa possibilidade.

Isso pois, quando as proposições jurídicas que estabelecem regras condicionais de precedência de um princípio sobre outro apresentam uma fundamentação racional, elas conseguem satisfazer a pretensão de correção. $E$, mediante a pretensão de correção formal exercida na produção e refutação de argumentos, num dado procedimento judicial específico, é que se qualifica o Direito moralmente e se realiza a integração entre o discurso prático geral ao discurso jurídico institucionalizado.

\section{REFERÊNCIAS}

ALEXANDER, Larry. Legal Objectivity and the Illusion of Legal Principles. In. KLATT, Matthias. (Ed.). Institutionalized Reason. The Jurisprudence of Robert Alexy. Oxford: Oxford University Press, 2012.

ALEXY, Robert. Teoria Discursiva do Direito. Rio de Janeiro: Forense Universitária, 2014

ALEXY, Robert. Prefácio. In: ALEXY, Robert. Direito, Razão, Discurso: estudos para a filosofia do direito. Tradutor Luís Afonso Heck. Porto Alegre: Livraria do Advogado Editora, 2010.

ALEXY, Robert. Fundamentação de normas e aplicação de normas. In: ALEXY, Robert. Direito, Razão, Discurso: estudos para a filosofia do direito. Tradutor Luís Afonso Heck. Porto Alegre: Livraria do Advogado Editora, 2010.

ALEXY, Robert. A análise lógica de decisões jurídicas. In: ALEXY, Robert. Direito, razão, discurso: estudos para filosofia do direito. Trad. Luís Afonso Heck. Porto Alegre: Livraria do Advogado Editora, 2010.

ALEXY, Robert. Sistema jurídico e razão prática. In: ALEXY, Robert. Direito, razão, discurso: estudos para a filosofia do direito. Trad. Luís Afonso Heck. Porto Alegre: Livraria do Advogado Editora, 2010. 
ALEXY, Robert. Teoria dos Direitos Fundamentais. Tradução Virgilio Afonso da Silva. São Paulo: Malheiros Editores, 2008.

ALEXY, Robert. Institucionalização da razão. In: ALEXY, Robert. Constitucionalismo discursivo. Trad. Luís Afonso Heck. Porto Alegre: Livraria do Advogado Editora, 2007.

ALEXY, Robert. Teoria da argumentação jurídica: a teoria do discurso racional como teoria da fundamentação jurídica. Trad. Zilda Hutchinson Schild Silva. 2. ed. São Paulo: Landy Editora, 2005.

ALEXY, Robert. Posfácio. In: ALEXY, Robert. Teoria da argumentação jurídica: a teoria do discurso racional como teoria da fundamentação jurídica. Trad. Zilda Hutchinson Schild Silva. 2. ed. São Paulo: Landy Editora, 2005.

ALEXY, Robert. La idea de una teoría procesal de la argumentación jurídica. In: ALEXY, Robert. Derecho y razón práctica. Trad. Ernesto Garzón Valdés. México: Distribuciones Fontamara, 1993.

ATIENZA, Manuel. A voltas com la ponderación. Anales de la Cátedra Francisco Suárez. n. 44. 2010.

ATIENZA, Manuel. As razões do Direito: Teorias da argumentação jurídica. Tradução Maria Cristina Guimarães Cupertino. 3. ed. São Paulo: Landy, 2003.

DUARTE, Écio Oto Ramos. Teoria do discurso e correção normativa do direito: aproximação à metodologia discursiva do direito. 2. ed. São Paulo: Landy Editora, 2004.

ENDICOTT, Timothy. Proportionality and Incommensurability. In: HUSCROFT, Grant (Ed.). Proportionality and the Rule of Law: rights, justification, reasoning. New York: Cambridge University Press, 2014.

GÜNTHER, Klaus. Teoria da argumentação no Direito e na Moral: justificação e aplicação. Tradução Cláudio Molz. São Paulo: Landy Editora, 2004.

HABERMAS, Jürgen. Teoria do agir comunicativo. Tradução Paulo Astor Soethe. São Paulo: Editora WMF Martins Fontes, 2012, v. 1.

HABERMAS, Jürgen. Direito e democracia: entre facticidade e validade. Trad. Flávio Beno Siebeneichler. 2. ed. Rio de Janeiro: Tempo Brasileiro, 2003. v.1.

JESTAEDT, Matthias. The Doctrine of Balancing - its Strengths and Weaknesses. In. KLATT, Matthias. (Ed.). Institutionalized Reason. The Jurisprudence of Robert Alexy. Oxford: Oxford University Press, 2012. 
KLATT, Matthias. (Ed.). Institutionalized Reason. The Jurisprudence of Robert Alexy. Oxford: Oxford University Press, 2012.

MORAIS, Fausto Santos de; ZOLET, Lucas. Constitutional rights expansion and contributions from Robert Alexy's theory. Revista Brasileira de Direito. v. 12, n. 2, p. 127-136, dez. 2016. ISSN 2238-0604. Disponível em: <https://seer.imed.edu.br/index.php/revistadedireito/article/ view/1505>. Acesso em: 14 fev. 2017.

STAFFEN, Marcio Ricardo; ARSHAKYAN, Mher. The legal development of the notion of human dignity in the constitutional jurisprudence. Revista Brasileira de Direito. v. 12, n. 2, p. 108-126, dez. 2016. ISSN 2238-0604. Disponível em: <https://seer.imed.edu.br/index.php/ revistadedireito/article/view/1560>. Acesso em: 14 fev. 2017.

STRECK, Lenio Luiz. Verdade e consenso. Constituição, hermenêutica e teorias discursivas. 4. ed. São Paulo: Saraiva, 2011.

TSAKYRAKIS, Stavros. Proportionality: An Assault On Human Rights? I-Con. v. 7. n. 3. 2009, p. 468-493.

Recebido em: dez/2016 Aprovado: fev/2017 